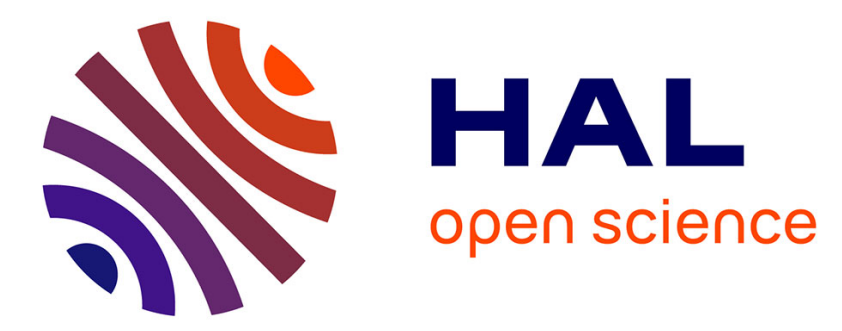

\title{
Computational fluid dynamics prediction and validation of gas circulation in a cheese-ripening room
}

Pierre-Sylvain Mirade, Jean-Dominique Daudin

\section{To cite this version:}

Pierre-Sylvain Mirade, Jean-Dominique Daudin. Computational fluid dynamics prediction and validation of gas circulation in a cheese-ripening room. International Dairy Journal, 2006, 16 (8), pp.920-930. 10.1016/j.idairyj.2005.08.007 . hal-02655568

\section{HAL Id: hal-02655568 \\ https://hal.inrae.fr/hal-02655568}

Submitted on 29 May 2020

HAL is a multi-disciplinary open access archive for the deposit and dissemination of scientific research documents, whether they are published or not. The documents may come from teaching and research institutions in France or abroad, or from public or private research centers.
L'archive ouverte pluridisciplinaire HAL, est destinée au dépôt et à la diffusion de documents scientifiques de niveau recherche, publiés ou non, émanant des établissements d'enseignement et de recherche français ou étrangers, des laboratoires publics ou privés. 


\title{
Computational fluid dynamics prediction and validation of gas circulation in a cheese-ripening room
}

\author{
Pierre-Sylvain Mirade*, Jean-Dominique Daudin \\ Equipe Couplage Transferts Transformations, Unité Qualité des Produits Animaux (QuaPA), INRA-Theix, 63122 St Genès Champanelle, France
}

Received 1 December 2004; accepted 26 August 2005

\begin{abstract}
This paper discusses the application of a computational fluid dynamics (CFD) approach to predicting air velocity patterns and circulation of an exogenous gas inside a pilot cheese-ripening room in 3 dimensions (3D). Comparison of numerical results with experimental data showed a fairly close agreement in the qualitative prediction and a few inaccuracies in the quantitative prediction of the air velocity patterns, with mean absolute differences of $0.12 \mathrm{~m} \mathrm{~s}^{-1}$ in half the volume of the ripening room and about $0.05 \mathrm{~m} \mathrm{~s}$ inside the stacks filled with cheese models. A sensitive study revealed that using the standard $k-\varepsilon$ model for modelling the turbulence of the flow in combination with the first-order upwind differencing scheme offered a good compromise solution between accuracy of results and computation time, given the 3D mesh of 1.2 million cells created. Moreover, numerical calculations indicated that using the blowing duct for adding an exogenous gas seemed to provide a more efficient solution for levelling off the gas distribution throughout the whole volume of the room than an injection performed directly into the core of the stacks.
\end{abstract}

(C) 2005 Elsevier Ltd. All rights reserved.

Keywords: CFD; Cheese; Ripening room; Air velocity; Gas circulation

\section{Introduction}

Computational fluid dynamics (CFD) solves fluid flow problems coupled with heat and mass transfers and turbulence phenomena in a given geometry by the use of a mesh where all the Navier-Stokes equations are solved across each mesh cell by means of an iterative procedure requiring specific algorithms. Due to the development of cheaper, more powerful computers and user-friendly commercial software packages, CFD techniques have been increasingly used in recent years in many areas of the food industry, as has been detailed in several reviews (Scott \& Richardson, 1997; Xia \& Sun, 2002). CFD techniques have been applied to industrial problems for predicting values for air velocities, composition of atmosphere and temperature fields inside food processing plants, including, for example, baking ovens (Verboven, Scheerlinck, De Baerdemaeker, \& Nicolaï, 2000a, b; Mirade, Daudin, Ducept, Trystram, \& Clément, 2004) and refrigerated rooms

\footnotetext{
${ }^{*}$ Corresponding author. Tel.: + 33473624592 ; fax: + 33473624089 .

E-mail address: mirade@clermont.inra.fr (P.-S. Mirade).
}

(Hoang, Verboven, De Baerdemaeker, \& Nicolaï, 2000; Mirade, Kondjoyan, \& Daudin, 2002; Foster, Barrett, James, \& Swain, 2002). In addition to the above-mentioned industrial applications, nowadays one of the most important and advanced applications of CFD in food processing is spray drying, with calculations aiming at improving spray-dryer design and operation (Straatsma, Van Houwelingen, Steenbergen, \& De Jong, 1999; Langrish \& Fletcher, 2001; Ducept, Sionneau, \& Vasseur, 2002).

Controlling airflow (air velocity, air change rate, and exchange with outside air) and climatic conditions (air temperature and relative humidity, gas concentration) inside cheese-ripening rooms is of paramount importance, because it determines both the efficiency and the homogeneity of cheese-ripening and weight losses. However, homogeneity in the distribution of climatic conditions is very hard to achieve at every single point of a ripening room. Consequently, industrial plants experience significant differences in the distribution of air temperature, velocity and relative humidity. For example, Pajonk (2001) reported differences greater than $10 \%$ in relative humidity inside an Emmental-ripening room, and attributed the 
observed damages on crust formation to these differences. In an $81 \mathrm{~m}^{3}$ ripening room filled with $10 \mathrm{~cm}$ diameter cheese models, Mirade, Rougier et al. (2004) measured air velocities ranging from less than $0.05-0.40 \mathrm{~m} \mathrm{~s}^{-1}$ inside the stacks and showed that heat and water transfer coefficients tripled when air velocity was increased from 0 to $0.45 \mathrm{~m} \mathrm{~s}^{-1}$ around plaster casts of cylinders $100 \mathrm{~mm}$ in diameter and $40 \mathrm{~mm}$ high. Falconer (1993) also highlighted significant heterogeneity in air velocity distribution in two cheese cooling stores, with air velocities ranging from 0.1 to over $2.5 \mathrm{~m} \mathrm{~s}^{-1}$, and, therefore, differences in the cooling of the cheeses. The heterogeneity in climatic conditions existing in cheese-ripening rooms means that cheesemakers have to regularly move cheeses to achieve even water losses and an even appearance in the cheese surfaces. Nevertheless, only a few studies on this very real problem can be found in the literature because most of these studies are confidential. Even the books dealing with cheeseripening processes (Eck, 1990; Mahaut, Jeantet, \& Brulé, 2000) do not give accurate information on the relationship between ventilation, indoor atmosphere and cheese quality; the authors only recommend a homogeneous atmosphere with low air circulation around the cheeses (air velocity not exceeding about $0.1 \mathrm{~m} \mathrm{~s}^{-1}$ ) and a "high enough" airflow rate in the room. Indeed, the role played by ventilation is complex and remains poorly quantified. Ventilation allows heat and humidity produced by the cheeses to be evacuated and also determines both weight losses and the gas concentrations $\left(\mathrm{CO}_{2}, \mathrm{O}_{2}, \mathrm{NH}_{3}\right)$ in the atmosphere surrounding the cheeses, which itself influences cheese ripening. For example, during the manufacturing of the Camembert cheese, the presence of ammonia and oxygen in the atmosphere of the ripening room makes it easier to reduce acidity on the surface of the cheese (Vassal \& Gripon, 1984) and for the Penicillia to grow (Roger, Desobry, \& Hardy, 1998), respectively. Furthermore, the presence of carbon dioxide in the indoor atmosphere would increase the opening of the curd of hard cheeses as Emmental, Gruyere and Comté by stimulating propionic acid fermentation (Mahaut et al., 2000).

The results presented in this paper stem from a research programme aiming at building instrumentation for controlling gas concentrations in the atmosphere of ripening chambers. The development of a system based on highperformance sensors coupled with information on airflow patterns would give ripening chamber operators greater flexibility in both controlling and adjusting the composition of the atmosphere, which would contribute to improving the consistency and the quality of the cheesemaking process. This paper is restricted to presenting the CFD prediction of air circulation in a pilot cheese-ripening room of $81 \mathrm{~m}^{3}$, the comparison of these numerical results with air velocity measurements, and the calculation of the circulation of an exogenous gas injected from points located either in the blowing duct or in the core of the cheese stacks. The geometry and operation of the pilotripening chamber were selected with the help of a plant designer as being representative of current standards in the industry.

\section{Materials and methods}

\subsection{Description of the pilot-ripening room}

The pilot-ripening room was $5.8 \mathrm{~m}$ long, $4.8 \mathrm{~m}$ wide and $2.9 \mathrm{~m}$ high, which gives an overall volume of $81 \mathrm{~m}^{3}$. Inside this room, 6 rows of 7 stacks of 16 racks of 21 cans (i.e. a total of 14,112 cans) were installed to obtain a filling pattern representing current industrial practice (Fig. 1). Free space according to the height between two consecutive racks was $10 \mathrm{~cm}$. As our interest in this study was the airflow inside the room and not the heat and water transport stemming from the interaction between the cheeses and their surroundings, we replaced cheeses by empty cans $10 \mathrm{~cm}$ in diameter and $4.4 \mathrm{~cm}$ high, i.e. inert objects presenting the same resistance against air circulation.

An air conditioning system comprising of two fans and two batteries and installed in a space located above the ceiling of the pilot-ripening room controlled the temperature and flow rate of the air blown into the room. The airflow rate was determined from the measurement of the pressure difference between two points of a diaphragm located in the duct supplying air to the blower duct made of textile material and placed in the chamber.

Inside the pilot-ripening room, the ventilation system was designed to mimic a common industrial configuration, namely an air conditioning system placed at the end of the room, extracting air in its lower part and blowing the conditioned air through a duct in its upper part. This system was composed of a $340 \mathrm{~mm}$ blowing duct made of textile material and a $315 \mathrm{~mm}$ suction duct (Fig. 1). The blowing duct running along the ceiling at half-width in the room was fitted on each side with several hundred holes $6 \mathrm{~mm}$ in diameter and divided into 3 rows. After being blown into the room, the air was extracted at $35 \mathrm{~cm}$ from the ground by means of a suction duct placed against a vertical wall at half-width in the room (Fig. 1). The suction duct was connected to the space located above the ceiling of the pilot ripening room in which the fans were installed. The full airflow rate blown into the room was $1600 \mathrm{~m}^{3} \mathrm{~h}^{-1}$, i.e. an air change rate of 20 volumes $\mathrm{h}^{-1}$, which corresponds to normal industrial practice.

\subsection{Air velocity measurements}

In the free spaces of the pilot ripening chamber, i.e. between the rows of the stacked racks and above the stacks, we applied a fast method set up at the laboratory and described in Mirade and Daudin (1998), using a specially built system (Fig. 1) to support and automatically move the measurement devices at a slow and fairly constant velocity. The measurement devices were multidirectional hot-film-type anemometers (model 8465, TSI, 

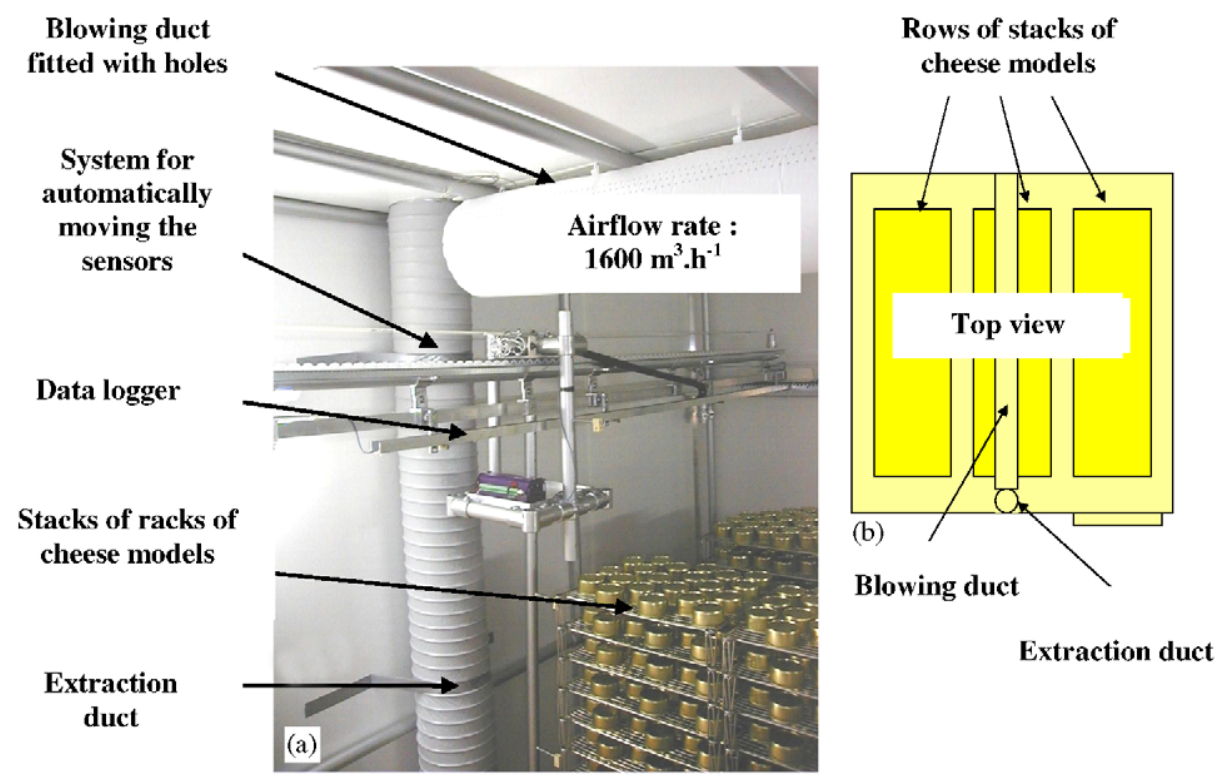

Fig. 1. Illustration of the geometry of the pilot cheese-ripening room studied in this work: (a) inside view, and (b) top view.

St Paul, Minnesota, USA) connected to a data logger (model DT600, DataTaker, Rowville, Australia). A travel velocity of about $1.5 \mathrm{~cm} \mathrm{~s}^{-1}$ was chosen for the experiments. Within the stacks of cheese models, recordings of air velocity must be averaged over at least $40 \mathrm{~s}$ at each measurement point to obtain a constant value for mean magnitude at an acquisition frequency of $0.2 \mathrm{~Hz}$ (a method called the standard average procedure). To perform a local investigation of the airflow pattern inside the stacks, we had to build telescopic antenna to move the sensors (model 8475 , TSI) into the free space (i.e. $50 \mathrm{~mm}$ ) between two stacked racks. To easily connect the measurements performed with the two methods, a regular experimental mesh was set up in the three space directions, with one measurement point every $19 \mathrm{~cm}$ in width, $21 \mathrm{~cm}$ in length and $20 \mathrm{~cm}$ in height. The air velocity magnitudes are given as coloured graphs in which each colour corresponds to a velocity level. A series of coloured graphs can be analysed to characterise the patterns of airflow into the chamber.

\subsection{CFD models and calculations}

From the geometrical configuration presented in Fig. 1, we used the Fluent 6.0.20 code (Anonymous, 2001) to build numerical models (Fig. 2) based on an unstructured three dimensional (3D) mesh of about 1.2 million hexahedral and tetrahedral cells. The inside of the blowing and extraction ducts was considered as being outside the computational domain, thus air inflow corresponded to the output from the holes of the blowing duct, and air outflow to the bottom of the extraction duct. About 5000 hexahedral cells were used for meshing each of the rows of the stacked racks of cheese models. Each hole of the blowing duct was meshed with at least 8 triangular cells, while the outlet area was meshed with 328 triangular cells.
To make it possible to link the fine mesh of the holes to the coarser mesh built into the other parts of the blowing duct, hexahedral 'boundary layer'-type cells were placed in the vicinity of the holes.

During the numerical calculations, airflow was considered as steady, incompressible, isothermal and turbulent. To assess the sensitivity of the calculations to turbulence modelling, main flow turbulence was taken into account using either the very popular standard $k-\varepsilon$ model (Launder \& Spalding, 1972), the renormalization-group (RNG) $k-\varepsilon$ model (Yakhot \& Orszag, 1986) or the $k-\omega$ model (Wilcox, 1998) far from the walls, which were assumed to be smooth and where the standard wall function was applied. The Simple algorithm (Patankar \& Spalding, 1972) was chosen for coupling pressure and velocity and introducing pressure into the continuity equation. The first-order or second-order upwind differencing scheme was also chosen in the computational models as a discretization scheme for the convection terms of each governing equation. First-order schemes are known to increase numerical discretization error (called numerical diffusion), especially when the flow is not aligned with the mesh, i.e. for triangular and tetrahedral grids (Hirsch, 1988). Although they therefore give less accurate results, better convergence of calculation is obtained when using first-order versus second-order schemes.

In the inlet area corresponding to the holes, an air velocity of $11 \mathrm{~m} \mathrm{~s}^{-1}$ determined from in situ measurements performed with a hot-film-type anemometer (model 8465, TSI) and a turbulence rate arbitrarily valued at $10 \%$ were specified. We chose $10 \%$ as we know from experience that the values of turbulence rate commonly range from $3 \%$ to $10 \%$ at the output of holes or conical jets, and exceed $50 \%$ at the output of fans. We also know that an underestimation of $10 \%$ or an overestimation of this value has 


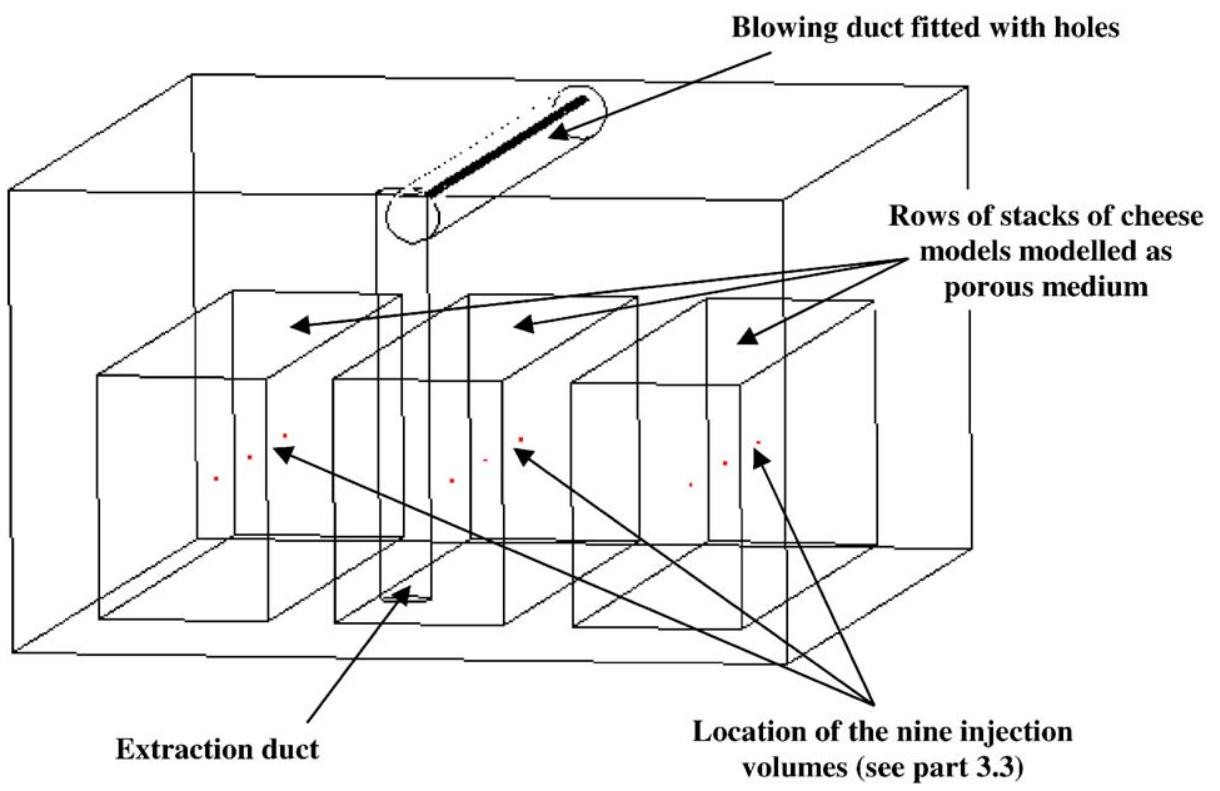

Fig. 2. Schematic description of the numerical models constructed from the geometry of Fig. 1.

a very limited impact on the outcome of the prediction of air velocity, especially when using first-order numerical schemes and $k-\varepsilon$ models. A classical outflow-type boundary condition was applied at the bottom of the extraction duct. This kind of boundary condition is conventionally used to model flow exits where details of the flow velocity and pressure are unknown prior to solution of the flow problem.

In all the models, the filling of the pilot-ripening room was taken into account as a porous medium, like a fluid volume in the fluent approach (Fig. 2). Porous media are modelled by the addition of a momentum source term to the standard fluid flow equations. The source term is composed of two parts: a viscous loss term (the first term on the right-hand side of Eq. (1)) and an inertial loss term (the second term on the right-hand side of Eq. (1)). In the case of a simple homogeneous porous medium, source term $S_{i}$ is formulated in the fluent code (Anonymous, 2001) as:

$$
S_{i}=-\left(\frac{\mu}{\alpha} v_{i}+C_{2} \frac{1}{2} \rho\left|v_{i}\right| v_{i}\right) \quad \text { where } \quad i \equiv x, y, z
$$

where $\alpha$ is the permeability $\left(m^{2}\right), C_{2}$ is the inertial resistance factor $\left(\mathrm{m}^{-1}\right)$, and $\mu$ is the dynamic viscosity of the fluid $\left(\mathrm{kg} \mathrm{m}^{-1} \mathrm{~s}^{-1}\right), v_{i}$ is the velocity according the direction $\left(\mathrm{m} \mathrm{s}^{-1}\right), \rho$ is the fluid density $\left(\mathrm{kg} \mathrm{m}^{-3}\right)$ and $x, y$, and $z$ are the three space directions.

To model turbulent flows through packed beds, Ergun (1952) established a semi-empirical correlation applicable over a wide range of Reynolds numbers. Comparing the Ergun equation with Eq. (1), the permeability $\alpha$ and inertial loss coefficient $C_{2}$ can be identified as:

$\alpha=\frac{D_{\mathrm{p}}^{2}}{150} \frac{\varepsilon^{3}}{(1-\varepsilon)^{2}}$
$C_{2}=\frac{3.5}{D_{\mathrm{p}}} \frac{(1-\varepsilon)}{\varepsilon^{3}}$

where $D_{\mathrm{p}}$ is the mean particle diameter $(\mathrm{m})$ and $\varepsilon$ is the void fraction, defined as the volume of voids divided by the volume of the packed bed region.

Although a stack of cheeses is not exactly like a packed bed (distances between cheeses can vary greatly, unlike the elements filling a packed bed) and although the cheeses could not be considered as spherical particles, we applied nevertheless the Ergun formulation to our configuration. However, we assumed that the values of $D_{\mathrm{p}}$ and $\varepsilon$ could change according to the three space directions, owing to the anisotropy of our porous medium. Thus, in our purely empirical approach, $D_{\mathrm{p}}$ was redefined as being a characteristic length of the elements filling the volume considered as a porous medium, and $\varepsilon$ remained a void fraction, but defined as the surface of voids divided by the total surface of the face of the porous volume perpendicular to the flow direction under study. In our configuration, the parameter $D_{\mathrm{p}}$ corresponds to the diameter of one can when considering vertical direction, and to its height in both transverse and longitudinal directions, as shown in Fig. 3 illustrating how the cans were arranged on a rack. The void fraction $\varepsilon$ could be easily calculated in relation to the vertical direction from the geometry of the base structure shown in Fig. 3. Hence, a value of $40 \%$ was determined (Peyne, 2002). On the other hand, for the transverse and longitudinal directions, the values of $\varepsilon$ were identified by visually comparing the measured fields to the air velocity fields calculated from many CFD calculations taking into account the filling of the ripening room as a porous medium with void fractions equal to $40 \%$ in the vertical direction and to $60 \%, 70 \%, 80 \%, 85 \%, 90 \%$ or $95 \%$ in the two other directions. Indeed, the calculation of the void 


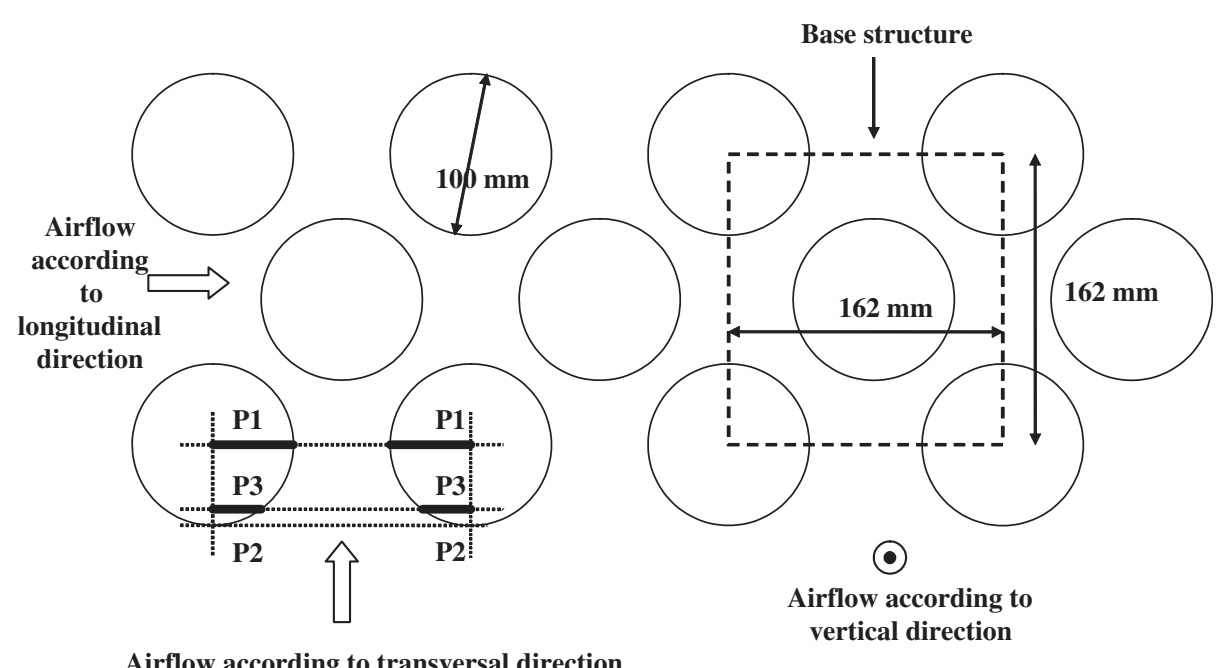

Airflow according to transversal direction

Cheese model height: $45 \mathrm{~mm} /$ Base structure height: $100 \mathrm{~mm}$

Fig. 3. Illustration of the layout of cheese models on one rack in relation to the three main airflow directions. A base structure was identified in the stacked racks to calculate the void fractions we needed to introduce into the porous medium formulation in order to model the filling of the ripening chamber in the CFD code.

fraction from the actual geometry of one stack proved impossible in these directions due to serious difficulties in accurately determining the total surface of cans perpendicular to the air circulation and consequently blocking it. We only knew that this surface ranged from surface P2, i.e. the vertical edge of a can, to a surface proportional to the length P1 (Fig. 3). Hence, a value of $90 \%$ was determined further to the visual comparison of the calculated and measured air velocity fields, corresponding to a cheese model surface proportional to the length $\mathrm{P} 3$, equal to $36 \%$ of the length P1 (Fig. 3). A figure of 90\% means a very poor resistance of the cheese models against the air circulation in the transverse and longitudinal directions, which is the result of the large free spaces between the cans, particularly between the top of the cans of one rack and the bottom of next rack located above.

Once these parameters were adjusted the numerical model was adapted to calculate how a gas added to air (namely $\mathrm{CO}_{2}$ ) circulates in the volume of the pilot-ripening chamber, with the aim of determining the optimal injection point for introducing an exogenous gas to accelerate the ripening process. Two possible configurations were investigated: first, using the blowing duct of the room to inject the additional gas via the holes (theoretically the simpler solution), or second, directly injecting the gas into the core of the stacks of cheese models by means of injection points represented in the numerical model by nine small cubes of $20 \mathrm{~cm}^{3}$. Each of the faces of these nine volumes injected $\mathrm{CO}_{2}$ at a velocity of $11 \mathrm{~m} \mathrm{~s}^{-1}$ to maintain the same quantity of gas introduced into the ripening chamber atmosphere when comparing this method with the first method where injection was performed through the holes of the blowing duct. The nine injection volumes of cubic shape were located at half-width, half-height, and at quarter, half and three-quarters of the length of the three rows of stacks, as illustrated in Fig. 2.

In order to model the $\mathrm{CO}_{2}$ transport (without chemical reaction) into the chamber, one additional convectiondiffusion equation needed to be solved, taking the following general form:

$\frac{\partial}{\partial t}\left(\rho Y_{\mathrm{CO}_{2}}\right)+\nabla\left(\rho \vec{v} Y_{\mathrm{CO}_{2}}\right)=-\nabla \vec{J}_{\mathrm{CO}_{2}}+R_{\mathrm{CO}_{2}}+S_{\mathrm{CO}_{2}}$

where $Y_{\mathrm{CO}_{2}}$ is the local mass fraction of the specie $\mathrm{CO}_{2}$ predicted by the fluent code (Anonymous, 2001) through the solution of Eq. (4), $R_{\mathrm{CO}_{2}}$ is the net rate of production by chemical reaction (equal to 0 in our configuration, where no reaction takes place), $S_{\mathrm{CO}_{2}}$ is the rate of creation by addition from the disperse phase plus any user-defined sources, and $\vec{J}_{\mathrm{CO}_{2}}$ is the diffusion flux of specie $\mathrm{CO}_{2}$ which arises from the concentration gradients.

In turbulent flows, the fluent code (Anonymous, 2001) computes the diffusion flux in the following form:

$\vec{J}_{\mathrm{CO}_{2}}=-\left(\rho D_{\mathrm{CO}_{2}, m}+\frac{\mu_{\mathrm{t}}}{S c_{\mathrm{t}}}\right) \nabla Y_{\mathrm{CO}_{2}}$

where $D_{\mathrm{CO}_{2}}, m$ is the diffusion coefficient for specie $\mathrm{CO}_{2}$ and $S c_{\mathrm{t}}$ is the turbulent Schmidt number, with a default setting of 0.7 .

In practice, the computation of Eqs. (4) and (5) is performed after total convergence in computation of the continuity and momentum equations has occurred, i.e. once the velocity field has been determined.

Many assumptions were made in the numerical model built, namely that no interaction occurred between the specie $\mathrm{CO}_{2}$ and the cheeses (thus no consumption by the cheeses), natural convection was neglected (given that the energy equation was not solved) and the gas extracted 
by the suction duct was not recycled back into the chamber through the blowing duct.

Calculations were performed on an Athlon $1900 \mathrm{XP}+$ PC with 1.5 Go of RAM. Computation time ranged from about $25-60 \mathrm{~h}$, depending on the turbulence model chosen and, especially, on the resolution or not of the additional transport equation for modelling gas circulation that required an unsteady computing.

\section{Results and discussion}

\subsection{Air velocity fields calculated}

The air velocity fields are represented as coloured velocity intensity maps ranging from the 'white' colour in areas in which air velocities were lower than $0.1 \mathrm{~m} \mathrm{~s}^{-1}$ to the 'black' colour when air velocities exceeded $0.4 \mathrm{~m} \mathrm{~s}^{-1}$. To make the flow pattern easier to assess inside the stacks where air velocities were low, all the magnitudes higher than $0.4 \mathrm{~m} \mathrm{~s}^{-1}$ are plotted in black, including all those that reached $1 \mathrm{~m} \mathrm{~s}^{-1}$ in the vicinity of the holes of the blowing duct. Given the symmetry in the distribution of air velocity according to a vertical plane crossing the blowing duct at $X=262 \mathrm{~cm}$, only the half-width of the room is plotted in Figs. 4 and 5.

Fig. 4 shows the air velocity pattern simulated around and into the stacks according to a vertical section located at half-length in the pilot ripening room and obtained from a CFD model accounting for turbulence using the standard $k-\varepsilon$ model and using the first-order differencing scheme. Analysis of this figure reveals that the air blown through the holes flows along the ceiling and the lateral wall with a velocity higher than $0.4 \mathrm{~m} \mathrm{~s}^{-1}$ (the values even reach $1 \mathrm{~m} \mathrm{~s}^{-1}$ in proximity to the blowing duct), before being separated into two parts when it reaches the top of the side stacks. From here, the first part of the air still flows down along the wall before entering the stacks, and the second part of the airflow appears to travel towards the blowing duct, giving rise to a swirl above the side stacks with air velocities equal to $0.2 \mathrm{~m} \mathrm{~s}^{-1}$ (Fig. 4). The swirl leads to the formation of a poor ventilated area above the stack located at halfwidth in the room and underneath the blowing duct, and in which air velocities do not exceed $0.1 \mathrm{~m} \mathrm{~s}^{-1}$. In the passages between the rows of stacks, the numerical model calculated air velocities ranging from 0.1 to $0.2 \mathrm{~m} \mathrm{~s}^{-1}$, with a slight increase in velocity when approaching the ground. Inside the side stacks of the cheese models, a marked gradient in relation to height appears as the air velocities peak at $0.3 \mathrm{~m} \mathrm{~s}^{-1}$ in the lower part of the stack while the upper part is clearly poorly ventilated, except for the last rack at the top of the stack owing to the swirl located above (Fig. 4). Furthermore, ventilation within the stack located in the middle of the room was clearly poor, whatever the height considered. Thorough analysis of the air velocities calculated at that site revealed that more than half these values are below $0.05 \mathrm{~m} \mathrm{~s}^{-1}$. The heterogeneity in air distribution highlighted by the calculations certainly has a strong impact on cheese-ripening factors, as we showed that water

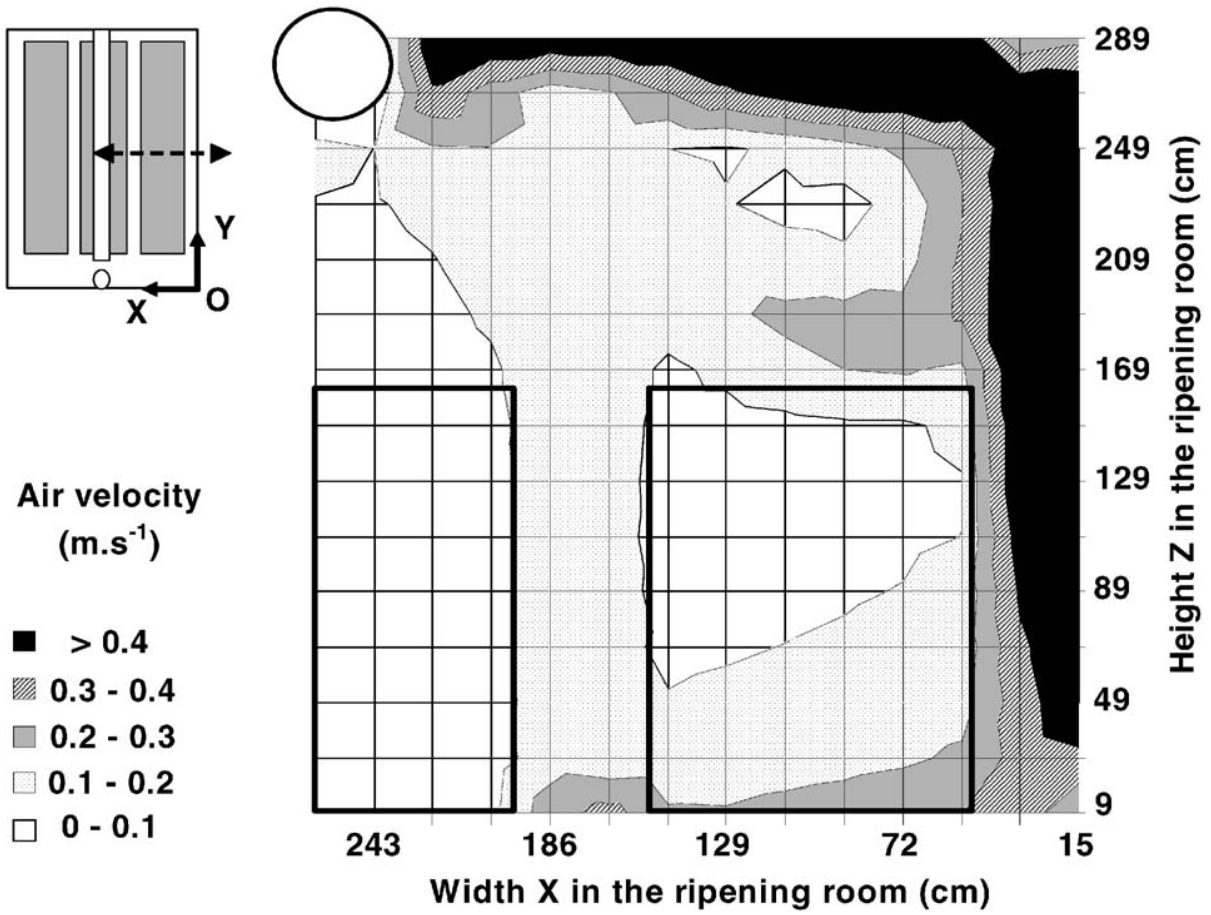

Fig. 4. Air velocity fields calculated both around and in the stacks on a vertical section located at half-length in the pilot-ripening room. The rectangles represent the outline of the stacks of cheese models, the circle indicates the location of the blowing duct, and the coordinates are given from the location of the walls. In the upper left-hand corner, a top view shows where the section crosses the room, and owing to symmetry, only half-width of the room is depicted. 

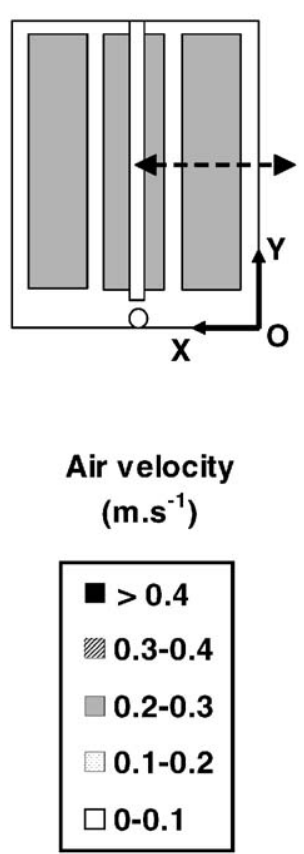

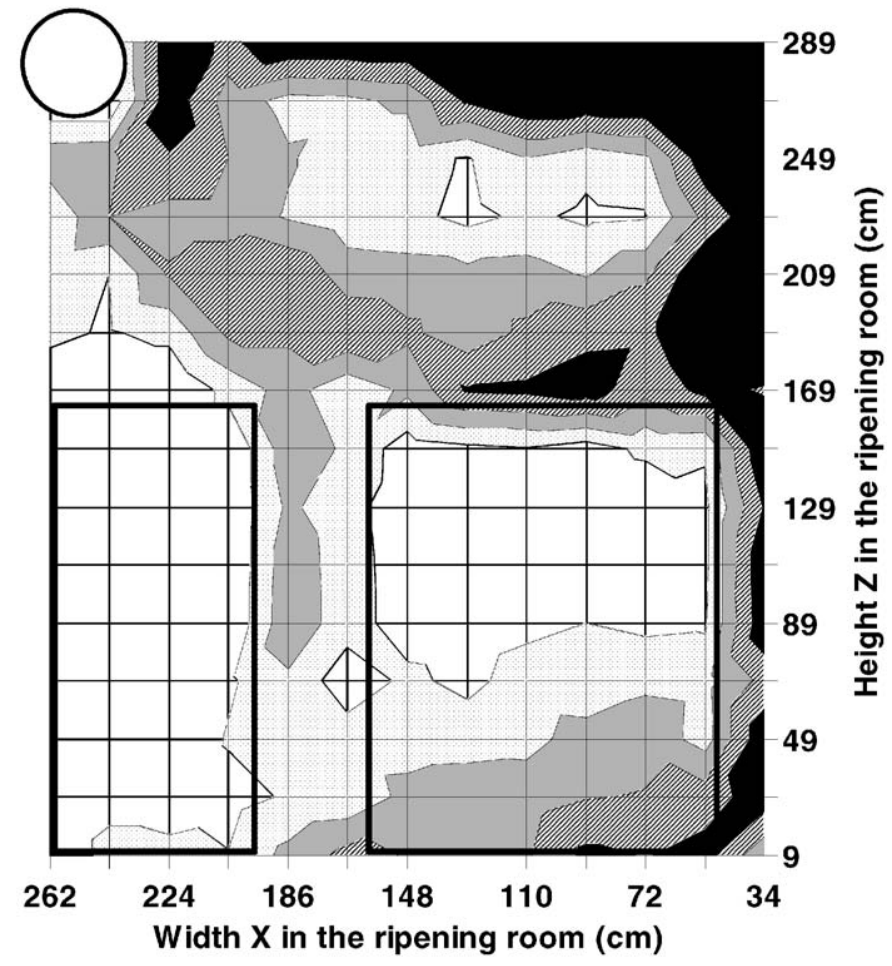

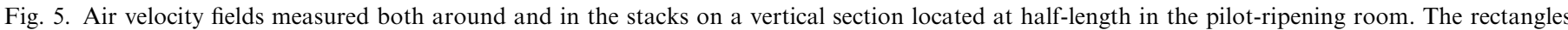

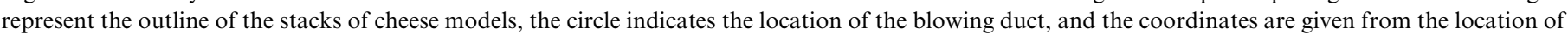

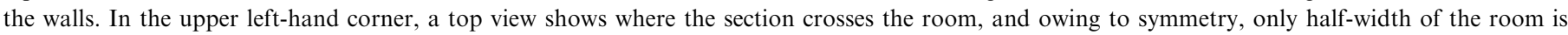
depicted. Each intersection line corresponds to a measurement point.

exchanges (thus water losses) at the surface of a cheese $10 \mathrm{~cm}$ in diameter and $4 \mathrm{~cm}$ in height could triple when the mean air velocity around the cheese is increased from 0 to $0.3 \mathrm{~m} \mathrm{~s}^{-1}$ (Mirade, Rougier et al., 2004).

The other calculated values confirm the airflow pattern depicted in Fig. 4, namely a poor ventilation in the stack located in the middle of the chamber and a marked gradient in the side stacks, but with a slight variation in magnitude as a result of a 3D effect due to the presence of the suction duct at one end of the room (Carles, 2003).

\subsection{Validation of the numerical results}

From a qualitative point of view, Fig. 5 showing the air velocities measured at half-length of the room (Rougier, 2002; Mirade, Rougier et al., 2004) confirms the findings resulting from the CFD model, i.e. higher air velocities along the ceiling and the side wall, the presence of a large swirl above the stacks, a marked gradient in air velocity distribution according to height in the side stacks, and poor ventilation in the stacks located in the middle. Comparison between Figs. 5 and 4 shows that the CFD model quite correctly simulates the airflow patterns inside the room and the stacks of cheese models, but with some discrepancies in the prediction of the magnitudes. The numerical model underestimates the air ventilation level in areas with strong gradients, as in the swirl or the side stacks. We can presumably attribute this inaccuracy to the integration into the model of the standard $k-\varepsilon$ model and of the first-order upwind differencing scheme, which are known to reduce strong gradients and give rise to numerical diffusion (Hirsch, 1988). Two other possible explanations for this limited accuracy may be put forward: (i) the use of porous media which roughly describe the preferential paths for airflow over the cheese models on the racks, or (ii) despite the steadily increasing power of computers and despite the 1.2 million cells used, the potential impossibility of discretizing the $3 \mathrm{D}$ computational domain with a mesh fine enough for obtaining truly independent results (Borth \& Suter, 1994). Dependence on mesh size was impossible to quantify because no additional cells could be added to the model due to the limited amount of memory size on the computer used.

From a quantitative point of view, Table 1 indicates that the discrepancy between simulation and measurement calculated from 4200 points of comparison came to about $0.12 \mathrm{~m} \mathrm{~s}^{-1}$ in half-volume of the room, $0.07 \mathrm{~m} \mathrm{~s}^{-1}$ in the right-hand side stacks, and $0.03 \mathrm{~m} \mathrm{~s}^{-1}$ in the stacks located in the middle, when using the standard $k-\varepsilon$ model for modelling turbulence and the first-order upwind differencing method as discretization scheme for the convection terms in the equations (Carles, 2003). As can be seen in Table 1, changing the turbulence model and working with second-order schemes does not improve the accuracy of the prediction of air velocity in the room or in the stacks, possibly due to the mesh created which does not have 
Table 1

Values of the mean discrepancies in air velocity between calculation and measurement as a function of turbulence modelling and discretization scheme

\begin{tabular}{|c|c|c|c|c|}
\hline \multirow{2}{*}{$\begin{array}{l}\text { Turbulence modelling/ } \\
\text { discretization scheme }\end{array}$} & \multirow{2}{*}{$\begin{array}{l}\text { Reaching convergence } \\
\text { Yes/no }\end{array}$} & \multicolumn{3}{|c|}{ Mean discrepancy of air velocity between calculation and measurement $\left(\mathrm{m} \mathrm{s}^{-1}\right)$} \\
\hline & & Right-hand side stacks & $\begin{array}{l}\text { Stacks located in the } \\
\text { middle }\end{array}$ & $\begin{array}{l}\text { Half the volume of the } \\
\text { ripening room }\end{array}$ \\
\hline$k-\varepsilon / 1$ st order & Yes & 0.07 & 0.03 & 0.12 \\
\hline$k-\omega / 1$ st order & Yes & 0.06 & 0.03 & 0.12 \\
\hline RNG $k-\varepsilon / 1$ st order & No & $0.05^{\mathrm{b}}$ & $0.02^{\mathrm{b}}$ & $0.13^{\mathrm{b}}$ \\
\hline$k-\varepsilon / 2$ nd order & No & $0.05^{\mathrm{b}}$ & $0.03^{\mathrm{b}}$ & $0.12^{\mathrm{b}}$ \\
\hline$k-\omega / 2$ nd order & No & $0.06^{\mathrm{b}}$ & $0.03^{\mathrm{b}}$ & $0.13^{\mathrm{b}}$ \\
\hline
\end{tabular}

\footnotetext{
${ }^{\mathrm{a}}$ The discretization scheme used in the numerical calculations was either a first-order or second-order upwind differencing scheme.

${ }^{\mathrm{b}}$ Since convergence was not reached and divergence did not occur (the residuals remained stable around a value lower than the value at the first iteration, but slightly higher than the convergence criterion), discrepancy between calculation and measurement was evaluated when the residuals were minimal during solving.
}

enough cells to give more accurate results. Regardless of the models chosen, the discrepancy between calculation and measurement still ranged from 0.12 to $0.13 \mathrm{~m} \mathrm{~s}^{-1}$ in half-volume of the room owing to the poor performance of modelling in the swirling area, and from 0.05 to $0.07 \mathrm{~m} \mathrm{~s}^{-1}$ in the side stacks and around $0.03 \mathrm{~m} \mathrm{~s}^{-1}$ in the other stacks. On the other hand, computation time increased dramatically (for example, it increased twofold when replacing the standard $k-\varepsilon$ model by the $k-\omega$ model), and convergence (and also divergence) of computation did not occur when using a second-order discretization scheme or the RNG $k-\varepsilon$ turbulence model; the residuals remained high and stable around a value lower than the value at the first iteration, but slightly higher than the convergence criterion of $10^{-4}$. Hence, the standard $k-\varepsilon$ model and the first-order upwind differencing scheme proved to be robust, timesaving and, given the mesh built, as accurate as the other models and schemes tested. The mean discrepancy in the air velocity prediction was $0.12 \mathrm{~m} \mathrm{~s}^{-1}$ in half-volume of the room and $0.05 \mathrm{~m} \mathrm{~s}^{-1}$ inside the stacks.

\subsection{Gas circulation}

CFD models were adapted to simulate the circulation of $\mathrm{CO}_{2}$ into the room from injection points located either in the blowing duct just at the output of the holes or in the core of each of the three rows of stacks at half-width, halfheight, and at quarter, half and three-quarters of the length, i.e. a total of nine cubic injection volumes of $20 \mathrm{~cm}^{3}$ (Fig. 2). This modelling aims at dynamically determining where and how an exogenous gas has to be introduced into the room so that a homogeneous distribution is reached as quickly as possible. From a practical point of view, the first solution consisting in adding gas through the blowing duct is better than the second solution, because it is much easier to implement inside the ripening chamber.

Fig. 6a displays mean concentration in $\mathrm{CO}_{2}$ versus time calculated for each of the three rows of stacks from an injection of $1 \%$ of $\mathrm{CO}_{2}$ performed through the holes of the blowing duct. This figure illustrates how the concentration remains the same, whatever the row of stacks, with a slight difference in the first 4 min of injection between the stacks located in the middle compared with the other stacks, which was almost certainly due to poor ventilation in that area. Besides the rapid achievement of homogeneity between the different rows, Fig. $6 \mathrm{a}$ also shows that the mean concentration exactly matches that of the injection points, after only $15 \mathrm{~min}$ of running.

Fig. 6b, which gives the mean concentrations calculated according to three vertical sections in the ripening room located near the extraction duct (at $177 \mathrm{~cm}$ distance), at half-length of the room and far from the extraction duct (at $492 \mathrm{~cm}$ distance), confirms the findings derived from the previous figure, namely homogeneity in $\mathrm{CO}_{2}$ distribution reached sufficiently rapidly, together with concentration values after $15 \mathrm{~min}$ equal to $1 \%$, i.e. the percentage at the inlet area. On account of a 3D effect due to the extraction of the air at one end of the room, slight differences between the three sections appear on Fig. 6b, especially for the farthest section from the extraction duct during the first 9 min of injection. However, using the blowing duct to add an exogenous gas appears to be an efficient solution for evening out gas distribution throughout the whole volume of the ripening room.

As regards the method consisting in injecting the gas by means of nine cubic volumes directly placed into the stacks, Fig. 7, which is a top view giving the $\mathrm{CO}_{2}$ concentration calculated in a horizontal plane crossing the nine injection cubic volumes, clearly highlights that this second method was inefficient in evening out gas distribution inside the room. After $15 \mathrm{~min}$ of injection, calculations indicate that $\mathrm{CO}_{2}$ concentration was far from being homogenous since it ranged from nearly $0-1 \%$ just around the injection volumes (Fig. 7). As soon as we leave these volumes, $\mathrm{CO}_{2}$ concentration inexorably drops as it is carried away by the airflow patterns before being extracted by the exit duct. Hence, mean gas concentration values were higher in the stacks located in the middle that are poorly ventilated than in the side stacks (Fig. 7). Analysis of other sections (data not shown) confirmed the heterogeneity in gas distribution. Even after $1 \mathrm{~h}$ of injection (data not shown), the calculations also revealed that $\mathrm{CO}_{2}$ concentration did not vary 


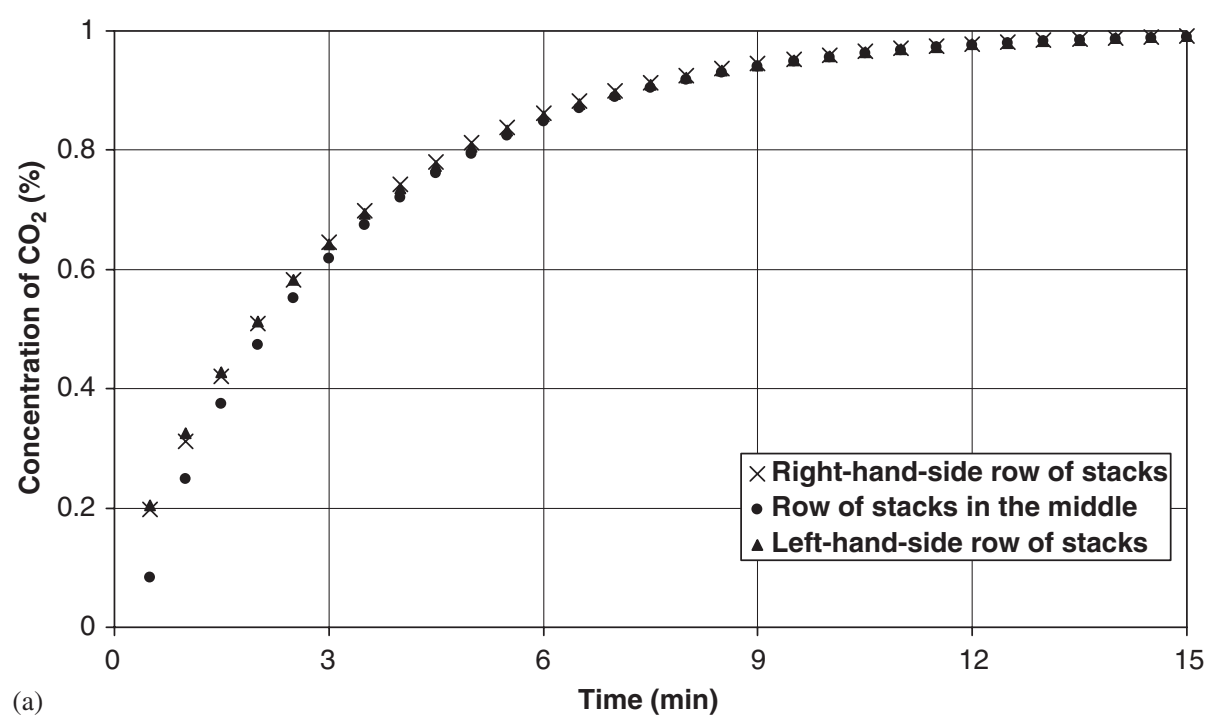

(a)

Time (min)

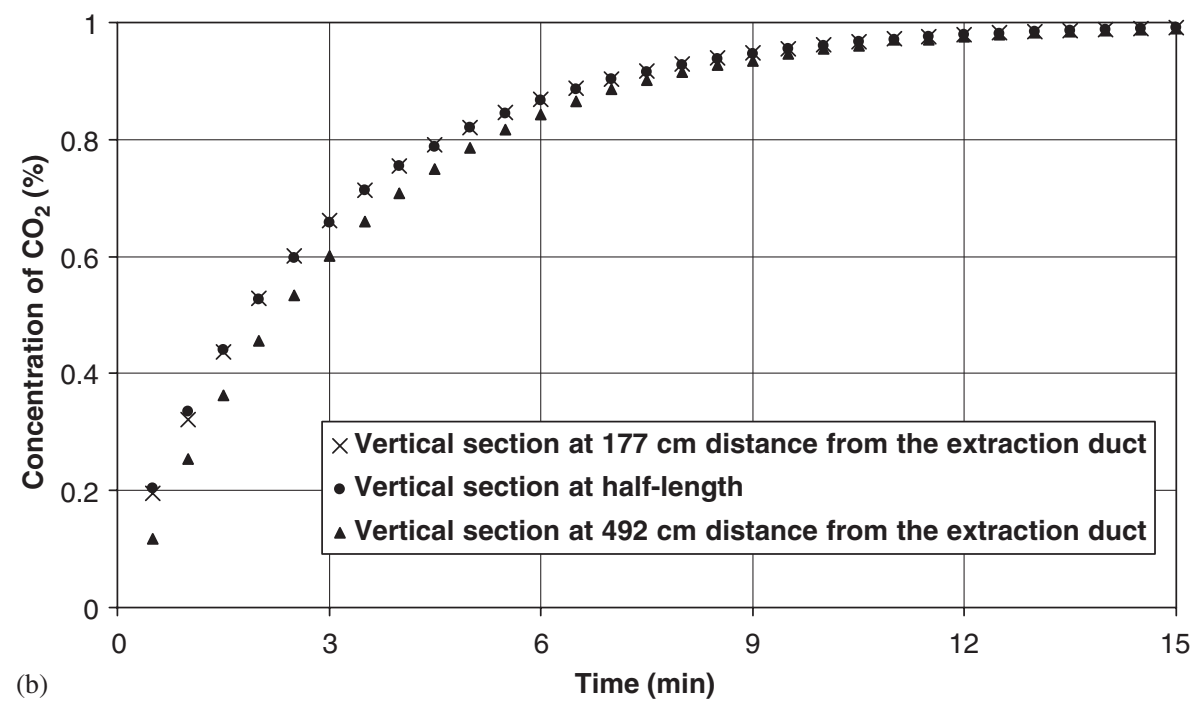

Fig. 6. Dynamic calculation of the evolution of the mean concentration of $\mathrm{CO}_{2}$ previously injected into the ripening room through holes in the blowing duct, for (a) the right-hand side, middle and left-hand side rows of stacks of cheese models, and for (b) three vertical sections located at $177 \mathrm{~cm}$ from the extraction duct, at half-length of the room, and at $492 \mathrm{~cm}$ far from the extraction duct, respectively.

after $10 \mathrm{~min}$, regardless of the location in the room, thus remaining heterogeneous. Unlike the first method, adding gas by means of injection volumes placed at different locations in the stacks leads to a heterogeneous distribution in the unit, based on the numerical results obtained. More homogeneous values would almost certainly have been obtained by increasing the number of injection volumes within the stacks, but this remains inconceivable from an industrial point of view. Indeed, each injection point requires a duct connected to a gas generator, thereby hampering cheese-makers who regularly move the stacks of cheese.

\section{Conclusion}

Although the representation of the filling of the plant with cheese models was significantly simplified in the numerical models we constructed, this work clearly shows that CFD techniques can be very useful tools for assessing the operation of industrial cheese-ripening rooms. In general, comparing calculations with measurements reveals a fairly close agreement in the prediction of airflow patterns within the pilot cheese-ripening chamber. However, in some regions, i.e. in the side stacks or in the swirl located above these stacks, the measurements indicated velocity gradients stronger than the model predicted. Further calculations were performed to identify a solution for introducing an exogenous gas into the ripening room in a homogenous way. To achieve this, the calculations indicated that using the blowing duct was a more efficient method than introducing the gas directly into the stacks.

However, in light of the results presented in this paper, it is very difficult to give quantitative recommendations on ventilation and indoor atmosphere in ripening chambers, and equally difficult to evaluate the consequence of the calculated gas distribution on cheese ripening. Further data 


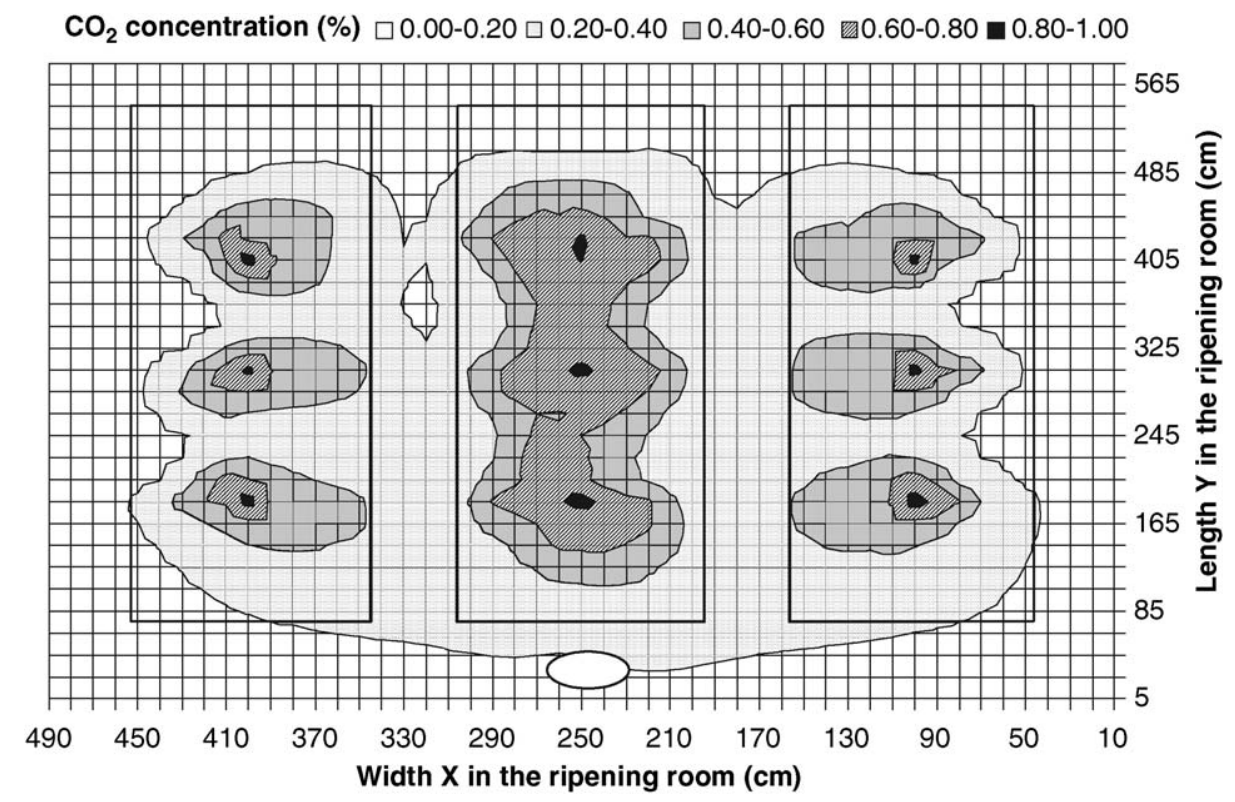

Fig. 7. Distribution of the mean concentration of $\mathrm{CO}_{2} 15 \mathrm{~min}$ after injection performed directly into the stacks of cheese models by means of nine injection volumes of $20 \mathrm{~cm}^{3}$, according to a top view spanning these volumes. The three rectangles represent the outline of the rows of stacks of cheese models, the ellipse indicates the location of the extraction duct, and the coordinates are given from the location of the walls.

is required to fully understand and quantify the interaction existing between the indoor climate of ripening rooms (air velocity, temperature and relative humidity, gas concentrations, renewal in fresh air, etc.) and the cheeses being ripened (weight losses, gas consumption and production at the cheese surface by microbial flora...). Studies are in progress in our laboratory, together with a scientific research aiming at determining appropriate coefficients to represent the rows of stacks of cheeses in the CFD model through porous media coupled with the general DarcyForchheimer formulation (Mirade, Agabriel, Brunet, \& Boulard, 2004).

Research is still needed to control cheese ripening by monitoring the indoor atmosphere, and to obtain evenly distributed ripening conditions around the cheeses. Further progress can be expected in the years to come due to the increasing calculation power of computers and progressively more flexible use of CFD codes. Thus, most probably it will be possible to fully simulate how a ripening room operates by implementing unsteady numerical models that accurately predict the heat, mass and gas exchanges between indoor atmosphere and several hundred cheeses being ripened.

\section{Acknowledgements}

The authors gratefully thank the French Ministry of Research and 'ARILAIT Recherches' for their financial support to this project involving the two INRA research laboratories of Grignon (D. Picque and G. Corrieu) and Theix (P.S. Mirade and J.D. Daudin), the industrial firms 'Safrair', 'Fromagerie de l'Ermitage' and 'Ysebaert', together with the ARILAIT sensor committee. We also wish to thank D. Peyne and A. Carles for their active participation in the numerical calculations, T. Rougier, L. Lasteyras, J.M. Auberger, S. Portanguen and A. Lasteyras for their contribution in the measurement of the air velocities in the ripening room used for validating the numerical results, and A.T.T. for having corrected the English version of this paper.

\section{References}

Anonymous. (2001). Fluent 6: User's guide. Lebanon, USA: Fluent Inc. Borth, J., \& Suter, P. (1994). Influence of mesh refinement on the numerical prediction of turbulent air flow in rooms. Fourth international conference on air distribution in rooms, Krakow, Poland, June 15-17, 1994. Gliwice, Poland: Silesian Technical University.

Carles, A. (2003). Analyse des échanges thermiques et de la circulation des gaz dans un hâloir de fromagerie: mesures globales dans l'appareil, mesures locales dans les piles de fromages et simulations numériques. Mémoire de stage d'ingénieur UTC Génie Chimique, 48p., Université de Technologie de Compiègne, Compiègne, France.

Ducept, F., Sionneau, M., \& Vasseur, J. (2002). Superheated steam dryer: Simulations and experiments on product drying. Chemical Engineering Journal, 86, 75-83.

Eck, A. (1990). Le fromage. Paris, France: Tec\&Doc Lavoisier

Ergun, S. (1952). Fluid flow through packed columns. Chemical Engineering Progress, 48(2), 89-94.

Falconer, R. M. (1993). Cooling air distribution in a cheese store. Meeting of Commissions B1, B2, D1, D2/3 of the Institut International du Froid/International Institute of Refrigeration, Palmerston North, New Zealand, September 1993. Paris, France: IIF.

Foster, A., Barrett, R., James, S. J., \& Swain, M. J. (2002). Measurement and prediction of air movement through doorways in refrigerated rooms. International Journal of Refrigeration, 25, 1102-1109.

Hirsch, C. (1988). Numerical computation of internal and external flows: Computational methods for inviscid and viscous flows. Chichester, England: John Wiley \& Sons Ltd. 
Hoang, M. L., Verboven, P., De Baerdemaeker, J., \& Nicolaï, B. M. (2000). Analysis of air flow in a cold store by means of computational fluid dynamics. International Journal of Refrigeration, 23, 127-140.

Langrish, T. A. G., \& Fletcher, D. F. (2001). Spray drying of food ingredients and applications of CFD in spray drying. Chemical Engineering and Processing, 40, 345-354.

Launder, B. E., \& Spalding, D. B. (1972). Mathematical models of turbulence. London, England: Academic Press Inc Ltd.

Mahaut, M., Jeantet, R., \& Brulé, G. (2000). Initiation à la technologie fromagère. Paris, France: Tec\&Doc Lavoisier.

Mirade, P. S., Agabriel, E., Brunet, Y., \& Boulard, T. (2004). Airflow modelling by computational fluid dynamics in an industrial plant filled with food products. Ninth International Congress on Engineering and Food, Montpellier, France, March 7-11, 2004. Montpellier, France: International Association for Engineering and Food.

Mirade, P. S., \& Daudin, J. D. (1998). A new experimental method for measuring and visualising air flow in large food plants. Journal of Food Engineering, 36, 31-49.

Mirade, P. S., Daudin, J. D., Ducept, F., Trystram, G., \& Clément, J. (2004). Characterization and CFD modelling of air temperature and velocity profiles in an industrial biscuit baking tunnel oven. Food Research International, 37, 1031-1039.

Mirade, P. S., Kondjoyan, A., \& Daudin, J. D. (2002). Three-dimensional CFD calculations for designing large food chillers. Computers and Electronics in Agriculture, 34(1-3), 67-88.

Mirade, P. S., Rougier, T., Kondjoyan, A., Daudin, J. D., Picque, D., \& Corrieu, G. (2004). Caractérisation expérimentale de l'aéraulique d'un hâloir de fromagerie et des échanges air-produit. Lait, 84, 483-500.

Pajonk, A. (2001). La solution flux variables alternants pour homogénéiser l'ambiance. Revue Laitière Française, 614, 20-22.

Patankar, S. V., \& Spalding, D. B. (1972). A calculation procedure for heat, mass and momentum transfer in three-dimensional parabolic flows. International Journal of Heat and Mass Transfer, 15, 1787-1806.

Peyne, D. (2002). Analyse numérique de l'aéraulique et des échanges gazeux dans un hâloir de fromagerie. Mémoire de fin d'études de DESS
Ingénierie Mathématique (41p), Université de Savoie, Bourget-du-lac, France.

Roger, B., Desobry, S., \& Hardy, J. (1998). Respiration of Penicillium camemberti during ripening and cold storage of semi-soft cheese. Lait, $78,241-250$.

Rougier, T. (2002). Caractérisation expérimentale de l'aéraulique d'un hâloir de fromagerie pilote: mesures de vitesses d'air et de coefficients de transferts chaleur/matière. Mémoire de DEA Sciences des Aliments (26p), Université Blaise Pascal, Clermont-Ferrand, France.

Scott, G., \& Richardson, P. (1997). The application of computational fluid dynamics in the food industry. Trends in Food Science and Technology, 8, 119-124.

Straatsma, J., Van Houwelingen, G., Steenbergen, A. E., \& De Jong, P. (1999). Spray drying of food products: 1 . Simulation model. Journal of Food Engineering, 42, 67-72.

Vassal, L., \& Gripon, J. C. (1984). L'amertume des fromages à pâte molle de type Camembert: rôle de la présure et de Penicillium caseicolum, moyens de la contrôler. Lait, 64, 397-417.

Verboven, P., Scheerlinck, N., De Baerdemaeker, J., \& Nicolaï, B. M. (2000a). Computational fluid dynamics modelling and validation of the isothermal airflow in a forced convection oven. Journal of Food Engineering, 43, 41-53.

Verboven, P., Scheerlinck, N., De Baerdemaeker, J., \& Nicolaï, B. M. (2000b). Computational fluid dynamics modelling and validation of the temperature distribution in a forced convection oven. Journal of Food Engineering, 43, 61-73.

Wilcox, D. C. (1998). Turbulence modelling for CFD. La Canada, USA: DCW Industries Inc.

Xia, B., \& Sun, D. W. (2002). Applications of computational fluid dynamics (CFD) in the food industry: A review. Computers and Electronics in Agriculture, 34(1-3), 5-24.

Yakhot, V., \& Orszag, S. A. (1986). Renormalization group analysis of turbulence: I. Basic theory. Journal of Scientific Computing, 1(1), 1-51. 